\title{
PRECARIZAÇÃO DA FORÇA DE TRABALHO E SAÚDE DOS TRABALHADORES: (IN)FLEXIBILIDADES NO “MUSEU DE GRANDES NOVIDADES"*1
}

\author{
Diego de Oliveira Souza \\ Ana Inês Simões Cardoso de Melo \\ Luiz. Carlos Fadel de V asconcellos
}

\section{Introdução}

A "pedra de toque" da dinâmica atual do capitalismo tem se constituído em um conjunto de ações que prometem "modernizar" as relações de trabalho, reduzir o desemprego e crescer as economias. Isso tem perpassado a concretização de variadas "reformas" que desregulamentam o trabalho, abrindo espaço para a propagação, de forma ainda mais vigorosa, do ideário da "flexibilidade" do trabalho em todo o mundo.

Esse aspecto possui relevo no debate contemporâneo, seja na agenda política dos vários países tomados pela direção neoliberal, na defesa intransigente sobre a necessidade de concretizar esse conjunto de ações; seja nos movimentos de resistência oriundos de setores da classe trabalhadora e, em alguma medida, no debate acadêmico. Nesse último caso, tem crescido o interesse pela investigação das várias dimensões e modalidades de precarização do trabalho, denominada pelo que se convencionou designar o conjunto de ações demandado pela "flexibilidade" do trabalho.

A mediação constituída na interface de tal processo com a saúde dos

DOI - 10.29388/978-65-86678-15-4-0-f.71-92

1 Expressão que toma de empréstimo da composição musical uma referência para tratar de grandes e antigas novidades que permeiam as contradições atuais entre a "flexibilidade do trabalho" e "inflexibilidade do capital", que subjazem à precarização da força de trabalho. CAZUZA; BRANDÃO, A. O tempo não para. In: O tempo não para. Rio de Janeiro: Polygram,1988. 
trabalhadores é importante no sentido de demonstrar as repercussões destrutivas por trás do discurso de "modernização" e que naturaliza a atual fase do capitalismo como sendo um destino inevitável. Os problemas de saúde seriam algo passível de mitigação, não sendo, necessariamente, um indicador do caráter destrutivo do capitalismo na sua face contemporânea (flexível), cabendo saber conviver com esses efeitos colaterais.

Obviamente, à perspectiva histórico-crítica incumbe a tarefa de combater esse discurso, mas não colocando outra no lugar a seu bel prazer. A tarefa consiste em desvelar os nexos fundamentais da realidade, como ela é. É nessa perspectiva que se inserem as contribuições apresentadas nesse capítulo, com o objetivo de realizar uma reflexão, fundamentada no debate teórico marxista, sobre o processo de precarização da força de trabalho e a "questão" da saúde dos trabalhadores. Tal objetivo pressupõe contribuir para o debate, apontando, ainda que preliminarmente, as limitações do horizonte que tem se construído da (e na) crítica à precarização. Obviamente, correlacionar tal processo à saúde será o ponto de chegada, confrontando-se com a mesquinhez que coloca o adoecimento sob a responsabilidade individual do trabalhador, ora ideologicamente travestido de "colaborador", "empreendedor", etc.

\section{Precarização da força de trabalho: "um museu de gran- des novidades"}

O primeiro aspecto para o qual chamamos atenção consiste no fato de que a precarização da força de trabalho demarca, política e juridicamente, a reestruturação produtiva que está em curso desde a década de 1970 e, no Brasil, mais efetivamente, a partir da década de 1990. O relevo social de tal processo se reflete na seara científica, sobremaneira entre aquelas tendências acadêmicas preocupadas em desvelar determinações mais essenciais e reverberações desse processo à classe trabalhadora.

Desde formulações seminais do conceito de "precarização social" (APPAY, 1997), por exemplo no contexto francês, as contribuições teóricoacadêmicas vêm nomeando os processos de desregulamentação do trabalho e de direitos sociais, a fim de expressar e/ou explicar a realidade das mudanças na 
produção e reprodução social. ${ }^{2}$ Sob o "paradigma da flexibilidade" (APPAY, 1997), o debate acadêmico, passou a formular tais processos a partir de categorias tais como a de precarização do trabalho, a precarização social do trabalho, por vezes de forma conjugada ao uso da denominação de "flexibilidade". Mais recentemente, outras formulações, com distinções entre elas, se voltaram à constituição do "precariado".

Autores de alcance internacional, como Mészáros (2006) e Fontes (2017), entre outros e com diferenças entre eles, têm entendido esse fenômeno do trabalho precário como um mosaico que engloba os trabalhos intermitentes, temporários, sem segurança social, porquanto avança o processo de desregulamentação trabalhista. Frente a processos que requerem a excessiva e perversa "flexibilidade do trabalho" frente à "inflexibilidade do capital", seja na contratação, seja no consumo, bem como no controle da força de trabalho, observa-se processos que não eliminam a necessidade de (mais) trabalho perfeitamente compatíveis com o declínio do trabalho positivado, isto é como emprego regular e protegido. (FONTES, 2017). A exata medida que desnuda a denominada "flexibilidade" é expressa por Mészáros (2006, p. 33-34), quando assim sintetiza:

2 No que concerne aos processos de precarização social - note-se sua distinção do termo precariedade, pois a formulação naquele contexto francês, usava o termo propositalmente a fim de demarcar os processos de colocação em precariedade e não sobre um estado ou estados relacionados à pobreza. Por um lado, tratava-se da precarização econômica, compreendendo as estruturas produtivas, a relação salarial, o desenvolvimento do desemprego de massa, a precarização dos estatutos e as formas de externalização e subcontratação do trabalho. Por outro, procurava-se enunciar a precarização da proteção social, a partir da transformação dos sistemas legislativos relacionados ao direito do trabalho e das empresas e às situações fora do trabalho, inclusive considerando a saúde no trabalho como reveladora dos processos de precarização social. Isto é, naquele contexto, tratava-se de conjugar dois campos sociológicos na análise dos processos de precarização - aquele voltado à análise do trabalho e o direcionado aos estudos sobre a pobreza e a integração social. (APPAY, 1997).

3 A expressão "flexibilidade" tem sido, muitas vezes, utilizada como equivalente à precarização do trabalho e, por vezes, para adjetivar os processos sociais que lhe subjazem, espécie de ressonância do debate "pós-fordista". Alves (2007, p. 126l) chega a evidenciar que "O processo de precarização do trabalho acaba por aparecer "sob o neologismo da flexibilização do trabalbo", também evidencia o desafio investigativo de se desvelar os processos de precarização do trabalho correlatos.

4 A respeito ver, por exemplo, Braga (2012; 2014; 2017) e Standing (2013; 2014). Também, entre nós, Alves $(2007 ; 2011)$ avança uma formulação que se volta para a "precarização do homem que trabalha". 
Os obstáculos reais enfrentados pelo trabalho, no presente e no futuro próximos, podem ser resumidos em duas palavras: 'flexibilidade' e 'desregulamentação'. Dois dos slogans mais apreciados pelas personificações do capital nos dias atuais, tanto nos negócios como na política, soam interessantes e progressistas. E, muito embora sintetizem as mais agressivas aspirações antitrabalho e políticas do neoliberalismo, pretendem ser tão recomendáveis, para toda criatura racional [...] pois a 'flexibilidade' em relação às práticas de trabalho - a ser facilitada e forçada por meio da 'desregulamentação' em suas variadas formas -, corresponde, na verdade, à desumanizadora precarização da força de trabalho.

Com efeito, esse fenômeno tem se colocado como um dos eixos do processo de "acumulação flexível” (HARVEY, 1992), caracterizando o momento contemporâneo do capitalismo, mas é preciso salientar, está longe de ser uma novidade, uma vez que se consubstancia enquanto "atributo modal da precariedade" estrutural da relação-capital (ALVES, 2007, p. 115). Entendemos que a precariedade é atributo inerente ao sociometabolismo do capital, tendo em vista que se constitui no fato de a força de trabalho ser a mercadoria especial que garante o processo de produção capitalista. Portanto, essa condição de precariedade social (estrutural) é indissociável de seu reflexo político-jurídico, com relevos diferentes ao longo da história face às próprias necessidades do capitalismo em transformação e à luta de classes. Para Alves (2007, p. 114, grifo no original)

O que chamamos de processo de precarização do trabalho é o processo de diluição (ou supressão) dos obstáculos constituídos pela luta de classe à voracidade do capital no decorrer do século XX. É a explicitação da precariedade como condição ontológica da força de trabalho como mercadoria. A precarização possui um sentido de perda de direitos acumulados no decorrer de anos pelas mais diversas categorias de assalariados.

A novidade nesse processo é o patamar social (e internacional) a que é alçada a precarização da força de trabalho em face do modelo atual de acumulação (flexível), ainda mais considerando sua relação histórico-dialética com o período que lhe antecedeu em alguns países do centro capitalista, no qual se forjou o ideal do pleno emprego no interior daquilo que se convencionou chamar de Estado de Bem-Estar Social e em meio a um processo de acumulação pelas vias "rígidas" do taylorismo/fordismo. 
É a aparente radical ruptura entre o padrão de acumulação anterior (rígido) e o atual (flexível) que cria a falsa sensação de a precarização ser uma invenção contemporânea. Não obstante, há um processo dialético de metamorfose do modelo de acumulação que se altera para manter, no seu âmago, aquilo lhe é vital: o processo de produção calcado na extração de mais-valia da força de trabalho (que demarca a própria precariedade), mas agora em uma articulação internacional que reflete a universalidade da atual crise (estrutural) do capitalismo (MÉSZÁROS, 2009).

Assim, a articulação histórico-ontológica existente entre a precariedade social originária do ato de mercadorizar a força de trabalho e a sua forma política de reposição (a precarização) não pode ser ignorada, sob o risco de: reduzir o debate à conjuntura, sem as conexões estruturais que lhe explicam; empobrecer o horizonte da luta de classes, em uma espécie de paralaxe na qual se mira na condição de emprego nos moldes anteriores e apenas de soslaio se olha para o cerne do processo de exploração.

Para Fontes (2017, p. 47), essas consequências se manifestam em alguns equívocos analíticos, com destaque para a confusão entre trabalho e emprego, o que tem, frequentemente, desdobrado-se em uma interpretação na qual o avanço tecnológico é concebido como a pedra fundamental do fim do trabalho. Porém, primeiramente, deve-se considerar que:

Sob o capital, o traço constitutivo mais forte do trabalho, a capacidade criativa, torna-se secundário para os que exercem a própria atividade (alienação). Para a grande maioria, o trabalho reduz-se à necessidade imperativa de homens e mulheres de garantir sua subsistência no mercado. Da relação social entre trabalho e capital e da atividade criativa saltamos para a relação jurídica 'emprego', forma ainda generalizada pelo capitalismo, mas em vias de transformação, na qual homens e mulheres estão totalmente disponíveis, durante a maior parte do tempo, aos seus empregadores, para realizar as tarefas ('trabalho') que lhes forem designadas.

Sem essa distinção, ignoram-se os traços ontológicos do que seja o trabalho - enquanto processo metabólico original no âmbito do ser social - e seus traços históricos enquanto processo de valorização sob regência do capital e que, pelas próprias necessidades do capital em administrar suas contradições pela via político-jurídica, forjou a condição de emprego. Que essa última condição esteja, agora, diluindo-se ante a "flexibilidade" não significa que a defesa do emprego seja para a classe trabalhadora algo desprovido de contradições e que, 
se protegida, afaste tal classe, um pouco que seja, do trabalho abstrato/alienado.

Considerando, então, que a fase atual do capitalismo destitui a condição de emprego - que se distingue do que seja o trabalho tal qual se organiza, de diferentes formas, no capitalismo - podemos chegar ao aspecto central do equívoco a ser evitado e que, nos termos de Fontes (2017, p. 50-51), sustenta a defesa do fim do trabalho:

A tecnologia é simultaneamente ameaça difusa de desemprego e promessa do fim do trabalho. A realização por máquinas de inúmeras tarefas é apresentada como garantia de um futuro no qual ninguém mais precisaria trabalhar (transformar a natureza), pois tudo seria produzido por tecnologias (muito ou pouco 'inteligentes'), liberando os seres sociais do trabalho, a começar pelas tarefas rudes ou repetitivas. O desemprego que a introdução capitalista de máquinas promove para intensificar a extração de valor é metamorfoseado em liberação do trabalho. A necessidade de trabalhar, porém, subsiste entre os seres sociais da sociedade capitalista, pois sem vender força de trabalho, tais expropriados não subsistem no mercado.

Ao reconhecer a articulação ontológica existente entre a mercadorização da força de trabalho e seu processo de precarização e ao ampliar o horizonte da luta de classes com vistas a emancipação humana, não só são desconstruídas as teses sobre o fim do trabalho pela mediação da tecnologia (visto a necessidade do capital se reproduzir articuladamente à subsistência dos expropriados no mercado), como fica demonstrado que, cada vez mais, é a extração de maisvalia da força de trabalho, de forma cada vez mais ampliada, a única saída para o capital enfrentar o seu ocaso, não podendo o capital prescindir do trabalho, ainda que o possa em relação ao emprego.

Dessa articulação, constata-se o horizonte que se desenha:

A globalização do desemprego e da precarização, até o momento, não pode ser remediada sem a substituição radical do sistema capitalista. Há poucos anos previu-se que, seguramente, todos os males sociais conhecidos, mesmo nos mais 'subdesenvolvidos' locais do mundo, seriam superados pela 'modernização', em conformidade com o modelo americano. Contudo, somos agora confrontados por algo diametralmente oposto àquele quadro otimista, pois as condições outrora confinadas, segundo a 'teoria do desenvolvimento' e a sabedoria governamental, às supostamente temporárias dificuldades do 'subde- 
senvolvimento' estão agora se tornando claramente visíveis mesmo nos países capitalistas mais desenvolvidos. (MÉSZÁROS, 2006, p. 32-33).

Constata-se, portanto, a dimensão universal do processo em curso e que, em constante metamorfose, não só demanda a organização da classe trabalhadora em um movimento que, sem abandonar o terreno da luta política pelos direitos e proteção social, mire "a substituição radical do sistema capitalista", conforme observado acima por Mészaros (2006, p. 32); assim como também, conceba esse mecanismo globalizado sem perder de vista as peculiaridades que se desdobram das formas como se consolida a acumulação flexível nas economias avançadas e dependentes do capitalismo.

Não obstante, deve ser advertido que em países de capitalismo dependente e periférico como o Brasil, os processos informados por este conceito de precarização social ou de precarização do trabalho são fundantes de sua formação social, uma vez que a constituição do assalariamento e de seu mercado de trabalho sempre contou com modalidades distintas de "trabalho independente" - isto é, inserções no trabalho sem carteira de trabalho assinada, por conta própria, autônomo, entre outras que não se circunscreveram ao trabalho como emprego, no sentido fordista, que pressupõe formalização e direitos sociais e trabalhistas correlatos (POCHMANN, 1999, 2001). Estas características encontram raízes econômico-políticas no próprio desenvolvimento do capitalismo nestas formações sociais, quanto na capacidade da regulação social amealhar conquistas frente às reivindicações dos trabalhadores no que concerne às relações e condições de trabalho.

De fato, como comentado por Mészáros (2006), cabe relembrar que as formulações sobre o trabalho como emprego, em convívio com formas pretéritas de inserção no trabalho, foram objeto de amplo debate, em décadas anteriores, sobre o desenvolvimento/subdesenvolvimento e a perspectiva da "integração social” em países dependentes como o Brasil. Reportava-se, naquelas formulações, à caracterização da informalidade e/ou do setor informal, com várias controversas, a fim de problematizar o processo tardio do assalariamento, em convívio com formas distintas de inserção no trabalho e com o desemprego. (MACHADO DA SILVA, 2002; OLIVEIRA, 2003; 2006).

Como visto, por relacionar a precarização do trabalho principalmente ao emprego, seja nos países avançados ou dependentes, a abordagem predominante coloca em destaque a ausência ou insuficiência da proteção social para atender ao precariado, sendo que Braga (2014), entre outros e por exemplo, destaca o aumento do número de acidentes de trabalho. De fato, ao lado dos 
transtornos mentais, das LER/DORT, várias produções recentes têm evidenciado sua incidência, nos últimos anos, relacionando acidentes de trabalho e o adoecimento a distintas modalidades de precarização do trabalho. (ANTUNES; PRAUN, 2015; FRANCO; DRUCK; SELIGMANN-SILVA, 2010; DRUCK, 2013).

Antes de voltarmos a "questão" da saúde dos trabalhadores com maior atenção, destacamos que, decerto, a diversificação da precarização se dá no mesmo ritmo das transformações na esfera produtiva, hoje conduzidas, sobretudo, pelas tecnologias em geral e, em particular, pelas tecnologias da comunicação e informação. Isso porque ela precisa ser entendida como fenômeno que sofre suas próprias metamorfoses, ainda que conservando seu caráter corolário à precariedade. Para Slee (2017) esse cenário conforma o que tem sido chamado de indústria 4.0, que se constitui em um terreno fértil para a consolidação da precarização do trabalho camuflada no discurso do empreendedorismo, economia compartilhada, peer-to-peer etc. Ratifica-se e, até mesmo, se amplifica, o clima de promessas com vistas a facilitar e "modernizar" a vida das pessoas e, especificamente, fazer com que os empresários e trabalhadores se libertem daquilo que seus propagandistas encaram como amarras arcaicas que impedem o "progresso". Tal modernização, em última instância, forja o horizonte de o trabalhador, sob posse das novas tecnologias, tornar-se patrão, empreendedor ou autogerir o seu trabalho.

Essas quimeras ganharam substância em meio aos serviços prestados por meio de plataformas virtuais, notadamente sob a forma de aplicativos $(A p p)$ de smartphones e que vem caracterizando a precarização da força de trabalho em sua face mais atual. Consoante Slee (2017), trata-se de uma artimanha na qual as empresas detentoras dessas plataformas invisibilizam sua responsabilidade trabalhista e fiscal, uma vez que o serviço parece ser uma relação direta entre o cliente e o prestador, ambos cadastrados na plataforma. $\mathrm{O}$ autor afirma que o caso mais representativo é o da Uber, que, desde 2013, vem oferecendo um serviço de transporte no qual motoristas são acionados pelos clientes por meio de um $A p p$, a partir do qual eles se comunicam e, inclusive, avaliam-se. Modelo que rapidamente se mundializou, colocando-se como uma alternativa aos trabalhadores repelidos do mercado formal e copiado por empresas similares, do mesmo ramo (99, Cabify etc.), ou de outros ramos (Ifood, Rappi, Uber Eats, etc.), dispostas a absorver segmentos do precariado.

Para Fontes (2017), esse fenômeno revela a ponta mais tecnológica da precarização da força de trabalho, ao passo que avança para formas bem peculiares de expropriação do trabalhador no que diz respeito ao contrato de traba- 
lho, dando um passo a mais rumo à diluição da concepção de emprego que a própria burguesia cunhou na história do capitalismo. Tal fenômeno, então denominado de uberização (SLEE, 2017), em alusão ao pioneirismo da Uber, conferiu outra dinâmica ao setor de serviços, fazendo com que as relações jurídicas e políticas ali imbricadas ficassem cada vez mais camufladas na fluidez virtual. Tanto Slee $(2017)^{5}$ quanto Fontes (2017) concordam no ponto que diz respeito à falácia por trás desse fenômeno, uma vez que os trabalhadores não alcançam o patamar de patrão, ainda que sejam donos do celular, do carro, moto ou bicicleta (isto é, dos meios mais imediatos necessários à realização do trabalho); ao contrário disso, continuam em uma relação de subordinação e exploração. Nesse quesito, Antunes (2019, p. 16, grifos no original) é esclarecedor:

O caso mais emblemático é da Uber, em que trabalhadores e trabalhadoras com automóveis próprios (seus instrumentos de trabalho) arcam com despesas de previdência, manutenção dos carros, alimentação etc., configurando-se como um assalariamento disfarçado de trabalho 'autônomo'. E, ao fazê-lo desse modo, as empresas se eximem dos direitos trabalhistas, burlando abertamente a legislação social em diversos países onde atuam. Com o trabalho online, que gera uma forte ampliação do tempo disponível para o trabalho, amplia-se mais o que venho denominando escravidão moderna na era digital.

Não obstante, cai-se o véu que encobre a essência desse processo, porquanto esses pseudo-empreendedores não passam de um segmento contemporâneo da classe trabalhadora que, por estar desprovido de direitos trabalhistas e oprimido pela ameaça do desemprego, submete-se a uma relação precária, sob o subterfúgio de trabalhar para si.

Nessa dinâmica complexa, com variadas formas de manifestação, é clarividente a multidimensionalidade da precarização da força de trabalho, com realce para sua dinamização tecnológica e com novos formatos de relações jurídicas e políticas que atravessam o mundo do trabalho, destituindo a condição de emprego. Porém, constata-se que, apesar de a precarização se apresentar com novos mecanismos, eles estão consignados à manutenção de uma velha relação, estruturalmente precária e, por isso, nem lhe conferem o status de invenção con-

5 Convém esclarecer que a perspectiva de Slee (2017) alcança o limite das lutas por direitos trabalhistas com vistas à defesa do emprego (regido por instrumentos contratuais burgueses), sem ir às raízes da relação de exploração que, estruturalmente, lhe subjaz. Contudo, no que concerne à caracterização fenomênica da uberização, esse autor traz importantes argumentos. 
temporânea nem concretizam a promessa de facilitação da vida mediante a suposta modernização, especialmente no que concerne à classe trabalhadora.

Nesse processo de metamorfose multidimensional da precarização, é possível vislumbrar alguns nexos possíveis com a "questão" da saúde dos trabalhadores, conforme abordamos a seguir.

\section{A “questão" da saúde dos trabalhadores e a multidimen- sionalidade da precarização da força de trabalho}

Os autores já referenciados, como de resto a produção teórico-acadêmica, têm evidenciado os processos de desproteção social e de desregulamentação dos direitos trabalhistas e sociais que acompanham os trabalhadores precarizados. Entre estes cabe destacar aqueles vinculados à "questão" da saúde dos trabalhadores, sendo importante breves considerações a respeito da concepção aqui adotada, distinguindo-se a "questão" e o "campo" pertinente às relações entre trabalho e saúde. Isto é, quando se trata da Saúde do(s) Trabalhador(es), cabe explicitar as relações trabalho-saúde sob duas perspectivas:

Na primeira - expressa no plural: saúde dos trabalhadores - situa-se a questão com sua pluralidade fenomênica, cujo sentido coletivo é mais condizente à sua dimensão social preponderante, determinada pela acumulação de riquezas pelo capital, decorrente da exploração da classe trabalhadora. $\mathrm{Na}$ segunda expressa no singular: Saúde do Trabalhador - situa-se o campo com uma ins titucionalidade limitada ao cenário de lutas restritas à forma como o próprio capital consente a organização da classe trabalhadora. (MELO; SOUZA; VASCONCELLOS, 2018, p. 1034).

A "questão" da saúde dos trabalhadores, em uma perspectiva crítica, é reportada, assim, ao advento do capitalismo e, mais precisamente, ao contexto da Revolução Industrial. A natureza das relações sociais de produção e reprodução social que ali se estabelecem alçam o trabalho e as condições de reprodução da força de trabalho a um novo patamar. As respostas dadas pelo capital e pelo Estado, desde então, foram construídas de diferentes formas, nos variados contextos, sendo possível discriminar três vertentes principais, quais sejam: a Medicina do Trabalho, a Saúde Ocupacional e a Saúde do Trabalhador. (LAURELL; NORIEGA, 1989; MELO, 1993; LACAZ, 1997; MINAYO-GOMEZ; THEDIM-COSTA, 1997; SOUZA; MELO; VASCONCELLOS, 2015; SOUZA, 2019). 
No Brasil, o campo da Saúde do Trabalhador é "resultante de um patrimônio acumulado no âmbito da Saúde Coletiva, com raízes no movimento da Medicina Social latino-americana e influenciado significativamente pela experiência operária italiana". (MINAYO-GOMEZ; VASCONCELLOS; MACHADO, 2018, p. 1964). Construída a partir de contribuições, também, das Ciências Sociais, na constituição da Saúde Coletiva no Brasil, esta concepção apreende o processo saúde-doença em suas dimensões biológica/individual e social/coletiva, conferindo centralidade à categoria marxista de processo de trabalho como referência de análise. (LAURELL; NORIEGA, 1989). Tratou-se, portanto, de um movimento de ruptura e reformulação das concepções anteriores "ainda hegemônicas que ao estabelecerem articulações simplificadas entre causa e efeito, numa perspectiva uni ou multicausal, desconsideram a dimensão social e histórica do trabalho e do binômio saúde/doença". (MINAYO-GOMEZ; VASCONCELLOS; MACHADO, 2018, p. 1964).

Esta perspectiva da Saúde do Trabalhador é a que se considera como referência, neste capítulo, sendo que ela se especifica em continuidade/ruptura com as demais e apresenta como principais pressupostos: o protagonismo dos trabalhadores como sujeitos centrais; a articulação entre investigação e intervenção; a universalidade e integralidade da atenção; a interdisciplinaridade e intersetorialidade das ações. No primeiro caso, trata-se de uma crítica, já formulada pelo Modelo Operário Italiano (MOI) (ODDONE et al., 1986), sobre a atribuição restrita aos profissionais de saúde, a serviço dos empregadores, sobre as questões de saúde dos trabalhadores, levando a formulação do princípio da "não delegação" e de valorização do saber do trabalho, ainda que em diálogo com os técnicos. A perspectiva de investigação-intervenção supõe as ações de vigilância dos ambientes de trabalho, que considera a importância da análise dos processos de trabalho para a formulação de propostas de intervenção. Para isso, é necessário um conhecimento interdisciplinar, que mobiliza, portanto, diferentes profissões e campos disciplinares, ao lado dos trabalhadores, para o conhecimento e elaboração de propostas de investigação/intervenção sobre os processos de trabalho, considerando-se que é a natureza mesma do objeto "saúde dos trabalhadores" que exige este diálogo interdisciplinar e, também, intersetorial. (MELO, 1993; MACHADO, 1997).

A abordagem da "questão" da saúde dos trabalhadores, nesta perspectiva interdisciplinar supõe o desenho e articulação de dois planos analíticos, como observam Minayo-Gomez, Vasconcellos e Machado: De um lado, "o contorno social, econômico, político e cultural - definidor das relações particulares travadas nos espaços de trabalho e do perfil de reprodução social dos dife- 
rentes grupos humanos". E, de outro, "o referente a determinadas características dos processos de trabalho com potencial de repercussão na saúde [...]" (MINAYO-GOMEZ; VASCONCELLOS; MACHADO, 2018, p. 1964).

Considerando-se a outra dimensão da análise, cabe levar em consideração o contexto econômico-político e sociocultural em que estes processos de trabalho se desenvolvem em suas relações com a saúde-doença e com a reprodução social. Neste sentido, cabe considerar as características macrossocietárias que determinam a organização dos processos de trabalho, suas condições de produção e de trabalho, nos marcos da gestão atual que, como foi visto, é marcada pela precarização da força de trabalho. E, considerando as relações entre produção e reprodução social, cabe se voltar, também, para a proteção social, em termos das políticas sociais levadas a efeito para a atenção à saúde dos trabalhadores.

Distintos autores têm se debruçado sobre as mudanças do trabalho, evidenciando sua incidência sobre a vida tanto dentro quanto fora dos locais de trabalho. Franco, Druck e Seligmann-Silva (2010) e Druck (2013), por exemplo, elaboram uma abordagem da precarização como fenômeno multidimensional, expresso a partir de cinco dimensões. ${ }^{6}$ Trata-se de formulação útil ao proporcionar um escopo analítico para desvelar e discutir nuances das relações entre precarização da força de trabalho e a saúde dos trabalhadores.

Segundo a formulação das autoras mencionadas, a primeira dimensão se refere aos "vínculos de trabalho e às relações contratuais" - ou como em Druck (2013, p. 62), "formas de mercantilização da força de trabalho" - relacionados à precarização do emprego e do mercado de trabalho, a partir de seu nivelamento "por baixo", permitindo a identificação das perdas de direitos trabalhistas e/ou de como estes são usufruídos efetivamente (integram-se, assim, o descanso remunerado, as férias, as jornadas de trabalho e sua extensão em horas extras, entre outros). Também estão aqui compreendidos os benefícios, usufruídos ou não, na forma de salários indiretos, tais como os "planos de saúde, transporte, alimentação, auxílio educação, dentre outros [...]”, bem como as perdas salariais, em geral, pela não adoção/cumprimento ou defasagem em relação aos acordos coletivos da categoria de trabalhadores mais 'estáveis"'. Esta dimensão está, portanto, relacionada à desestabilização dos trabalhadores mais “estáveis" e, juntamente, com os trabalhadores precários, os levam "a metaboli-

${ }^{6}$ Nos detemos aqui em Franco, Druck e Seligmann-Silva (2010) e Druck (2013). Druck (2013) explicita que a construção destas dimensões da precarização do trabalho visa a construção de indicadores e menciona, ainda, sua reelaboração, que parece acompanhar o processo investigativo de projeto de pesquisa. 
zarem, cotidianamente, a competição desenfreada, a insegurança e a instabilidade, terrenos em que prolifera e se move a gestão pelo medo", frequentemente associada ao desgaste mental (FRANCO; DRUCK; SELIGMANN-SILVA, 2010, p. 231).

Nesse sentido, nota-se que a precarização da força de trabalho se recoloca a todos os trabalhadores e a todas trabalhadoras, ainda que a positividade do emprego e os direitos que lhe foram agregados sejam vistos, por vezes, como "privilégios", o que levaria à falsa suposição que os processos de precarização não atingiriam àqueles inseridos em relações formais $\mathrm{e}$, por vezes, com um conjunto de direitos trabalhistas e sociais. Como se argumenta, a precarização da força de trabalho se alimenta em conjunto com as diferentes dimensões que a perpassam, uma vez que ineliminável sob o capitalismo ainda que continuamente re-posta.

A "organização e as condições de trabalho" constituem a segunda dimensão da precarização, conforme Franco, Druck e Seligmann-Silva (2010, p. 231), sendo possível nela aferir a avaliação de desempenho e a intensificação do trabalho, considerando as "metas inalcançáveis e [o] ritmo intenso do trabalho", com o auxílio tecnológico da microeletrônica (incluindo-se aqui as inovações trazidas com a indústria 4.0). As autoras ainda acrescentam: "A forte pressão de tempo somada à intensificação do controle ou da instrumentalização do medo à demissão conduzem à intensificação do trabalho", com a concorrência e competitividade jogando um papel importante na intensificação do trabalho, incidindo tanto na sociabilidade quanto na saúde mental dos trabalhadores. Podem ser identificados processos de hiperatividade, relacionados à "compulsividade e a autoaceleração", não sendo favorecidos tempos voltados "a pausas, repouso [e] recuperação do cansaço".

De fato, são estreitados, também, os espaços de "tempo de viver e conviver fora do ambiente de trabalho" (FRANCO; DRUCK; SELIGMANN-SILVA, 2010, p. 232), observando-se os limites entre produção e reprodução da vida - necessários para fazer frente ao desgaste físico e mental proporcionado pelo trabalho (LAURELL; NORIEGA, 1989). Também, na organização dos processos de trabalho, incide a estratégia de polivalência sobre a identidade dos trabalhadores e a experiência de suas especialidades anteriores, bem como a rotatividade entre diferentes espaços de trabalho, com distintos contratos, podendo potencializar a exposição aos distintos riscos e/ou cargas do trabalho. 
Associada às anteriores, a terceira dimensão se volta diretamente para a "precarização da saúde dos trabalhadores". ' Aqui, observa-se a maior fragilização orgânica, existencial e/ou identitária que a organização do trabalho tem trazido aos trabalhadores, quando se constata a "intensificação da multiexposição", que se soma a limitações na atuação dos serviços de saúde das empresas (e demais organizações que executam processos de trabalho), sob o argumento, no Brasil, de uma suposta contenção de custos. São suas expressões a ausência e/ou insuficiência de treinamento quanto a riscos; "na diluição das responsabilidades em relação a acidentes, adoecimentos e falhas na prevenção, além do predomínio das medidas de proteção individual em detrimento da proteção coletiva e das políticas preventivas". (FRANCO; DRUCK; SELIGMANN-SILVA, 2010, p. 232).

Com essa dimensão, pode-se constatar a fragilização até mesmo das respostas do capital dadas à "questão" da saúde dos trabalhadores por meio dos campos da Medicina do Trabalho e da Saúde Ocupacional. Por um lado, ocorre a invisibilidade e a desresponsabilização das empresas em relação à saúde desse segmento precarizado da classe trabalhadora, uma vez que eles escapam ao público sobre o qual esses tradicionais campos costumam intervir e, por outro lado, tem deslocado esses mesmos campos do centro das ações necessárias à acumulação flexível, porquanto joga cada vez mais a responsabilidade sobre a saúde para o trabalhador individualmente. Sobre isso, merece ser destacado o fato de que, esses campos conseguiram algum nível de consolidação ante a regulamentação da condição de emprego agora destituída com a "flexibilidade". Por conseguinte, eles mesmos sofrem reformulações, perdendo espaço no âmbito empresarial ao seguirem reformas trabalhistas, ampliação da terceirização ou o deslocamento do empregado para a pseudo-condição de empreendedor.

Com isso, a sujeição dos trabalhadores as atuais condições de trabalho é favorecida pelos frágeis vínculos de trabalho, em suas diferentes modalidades, tais como o trabalho terceirizado, temporário, teletrabalho, a uberização etc., no que podemos constatar um entrelaçamento com a primeira dimensão da precarização aqui mencionada. Artifícios diversos são levados a efeito a fim de garantir o cumprimento de metas e a aceleração do ritmo de trabalho, em detrimento da saúde no trabalho. Diante disso, verifica-se que "o ambiente atual de trabalho [...] é extremamente fértil para a propagação dos 'maus tratos'. Eles são incentivados por uma perversidade que contamina o ambiente, estimula condutas

Em Druck (2013) esta dimensão é denominada como “condições de segurança no trabalho". Mantivemos a versão anterior, por sua proximidade à perspectiva crítica de Saúde do Trabalhador que já contempla segurança. 
que [...] causa[m] dano, sofrimento e até mesmo doenças" (DRUCK, 2013, p. 70). Para nós, torna-se inevitável, portanto, pensar a precarização da saúde dos trabalhadores de modo associado também a esta dimensão.

O processo de "compressão espaço-temporal" (HARVEY, 1992), também pode ser verificado na não compatibilização entre "os tempos sociais do trabalho (ritmos, intensidade, regimes de turnos, hora extra, banco de horas)" e "os biorritmos dos indivíduos, gerando acidentes e adoecimentos, destacandose, internacionalmente, o crescimento de dois grupos de patologias - o das LER/DORT e o dos transtornos mentais". (FRANCO; DRUCK; SELIGMANN-SILVA, 2010, p. 232).

De fato, a "estrutura temporal do trabalho" é um importante componente das "situações de trabalho", determinando à exposição a cargas e riscos e ao desgaste mental no trabalho (SELIGMANN-SILVA, 1994). Fundamentadas na produção acadêmica, Franco, Druck e Seligmann-Silva destacam, por exemplo, "Os transtornos do ciclo vigília-sono", que são comuns no trabalho noturno e em turnos, que "muitas vezes, aparecem associados (em comorbidade) ao quadro de fadiga patológica [...] e o Esgotamento Profissional (Síndrome de Burnout)" (2010, p. 232 - grifos no original), estando relacionados a casos de depressão e de processos psicossociais, bem como "os riscos de hipertensão arterial e doença coronariana configurados pela pressão temporal em profissionais submetidos de forma continuada ao work-stress, entre outras patologias [...]”. Destaca-se, nesse sentido, que muitos destes agravos expressam a "incompatibilidade entre os tempos sociais do trabalho/vida e a capacidade adaptativa da fisiologia e dos biorritmos humanos". (FRANCO; DRUCK, SELIGMANN-SILVA, 2010, p. 232 grifos no original).

Vale destacar que a aceleração do ritmo com vistas ao cumprimento de metas está presente, de diferentes modos, desde as fases mais iniciais do processo de produção capitalista - basta lembrarmos que o pagamento por produtividade, consoante Fontes (2017, p. 47), já está presente na obra de Marx quando da análise do "salário por peça". Nas palavras da autora: "Marx já assinalava a tendência a uma opacidade ainda maior das relações entre capital e trabalho através do pagamento de salários por 'peças', quando a remuneração do trabalhador depende não da jornada contratada, mas de sua produção".

Esse mecanismo, na sua face contemporânea, (re)apresenta-se como uma força propulsora que leva o trabalhador a cumprir as metas, produzir mais, gerando-lhe a falsa sensação de aumentar seu salário, sem que perceba que, em termos relativos, continua diminuindo a parcela que recebe em relação à totalidade da produção. Assim, o pagamento por produtividade leva o trabalhador a 
enxergar vantagens no prolongamento da jornada ou intensificação do ritmo, mesmo que isso custe a sua saúde, o que só se acelera e se complexifica pela mediação das plataformas tecnológicas. A falsa sensação de controle sobre os meios mais imediatos de trabalho, ou sobre a quantidade de horas que se trabalha, esconde o fato de que os conglomerados financeiro-tecnológicos continuam a manter "o controle econômico do processo na parte que lhes interessa [...]”. (FONTES, 2017, p. 57). Ao trabalhador resta a precarização que, aí sim, sem disfarces, expressa-se no seu adoecimento, seja pela violação do biorritmo individual, seja pelo sentimento de frustração e culpa com o não cumprimento das metas, que parece ser de exclusiva responsabilidade individual.

A quarta dimensão, apontada pelas autoras, se refere à "fragilização do reconhecimento social, da valorização simbólica e do processo de construção das identidades individual e coletiva". (FRANCO; DRUCK; SELIGMANNSILVA, 2010, p. 232). Frente a formulações que apontam a possibilidade de declínio do trabalho, as autoras reafirmam o seu papel, que "ainda ocupa um espaço/tempo central na vida social e individual, [sendo que] sua precarização dificulta o processo de identificação e construção de si, tornando mais complexa a alienação/estranhamento do trabalho", de acordo com a formulação de Antunes (2002). (FRANCO; DRUCK; SELIGMANN-SILVA, 2010, p. 232).

De fato, ainda segundo as autoras, irá se consolidar no imaginário social "a noção de descartabilidade das pessoas, de naturalidade da insegurança e da competição de todos contra todos [...]". Neste processo atinge-se "as identidades individual e coletiva, bem como a dimensão ética e a dignidade - o cerne do ser humano". (FRANCO; DRUCK; SELIGMANN-SILVA, 2010, p. 232). Perspectiva que encontra convergência com a abordagem de Alves (2007; 2011) quando formula a "precarização do homem que trabalha".

A "representação e organização coletiva (sindical)" dos trabalhadores constitui-se em dimensão essencial frente às estratégias atuais do capital e que, também, é apontada por Franco, Druck e Seligmann-Silva, a fim de caracterizar a quinta e última dimensão da precarização. Articulando-se à terceirização, a precarização atinge não apenas a identidade individual e coletiva, mas também "conduz à fragilização dos agentes sociais". (2010, p. 232) Com a uberização, a estratégia ideológica que avança a ideia do empreendedorismo e a instituição de um segmento do setor de serviços sem o legado histórico da organização sindical e política, dificulta-se a própria identificação de motoristas, entregadores e outros "trabalhadores de $A p p$ " com a classe trabalhadora e, por conseguinte, confere inconsistência às parcas tentativas de organização (FONTES, 2017). 
No caso da terceirização, esta tem efeitos políticos na pulverização e enfraquecimento sindical, com ameaças a sua representatividade, na justa medida de sua crescente divisão e fragmentação em diferentes sindicatos, por categoriais profissionais, "com atuações competitivas entre si" (FRANCO; DRUCK; SELIGMANN-SILVA, 2010, p. 233). Neste processo, verifica-se a discriminação entre os próprios trabalhadores - "estáveis" e terceirizados -, ao tempo em que limitam-se e exigem-se novas respostas e possibilidades de enfrentamento, tanto individual quanto coletivamente. Esta fragilização terá repercussões como insegurança, como desproteção para cada trabalhador/a, bem como coletivamente, podendo estar na base, inclusive, de transtornos psíquicos. (FRANCO; DRUCK; SELIGMANN-SILVA, 2010).

Desses processos desdobram-se consequências que, novamente, convergem à precarização da saúde dos trabalhadores, pois, além das consequências referidas para a Medicina do Trabalho/Saúde Ocupacional, as investidas são ainda mais severas para o "campo" da Saúde do Trabalhador, notadamente pela convergência das duas últimas dimensões da precarização citadas. Ora, a dificuldade de construção da identidade social e coletiva do trabalhador enquanto tal, mistificada pela narrativa da colaboração e/ou do empreendedoris mo, juntamente à fragilização da organização sindical e política para luta de classes, constituem-se em relevante obstáculo à efetivação do protagonismo que os trabalhadores devem exercer no interior do campo, tornando-o incipiente mesmo considerando suas possibilidades nos limites do capitalismo.

Mesmo o campo da Saúde do Trabalhador não pode - face ao sistema do capital, do qual ele faz parte (enquanto campo científico e político-institucional) - alcançar à "questão" na sua totalidade (SOUZA, 2019), apenas acessível num movimento de enfrentamento do capital desde suas bases, visando destituir a exploração da força de trabalho (consolidada mesmo na condição de emprego protegido, nos moldes do Estado de Bem-Estar Social), portanto, superando não só a precarização, mas a precariedade estrutural vinculada ao trabalho abstrato; isto é, superando o próprio trabalho alienado. O horizonte prioritário não pode deixar de ser este, sob pena de que, historicamente, esse processo seja reposto, de diferentes formas, mas sempre a pauperizar a classe trabalhadora e destruir a sua saúde. 


\section{Considerações Finais}

A precariedade da força de trabalho é estrutural ao capitalismo, sendo re-posta de acordo com as necessidades e interesses da acumulação no processo histórico-social. Em todas as suas dimensões, repercute, de alguma maneira, para o processo saúde-doença dos trabalhadores, constituindo, inclusive, uma dimensão específica na qual há o aumento da exposição aos riscos e às cargas, ao passo que se restringe o alcance dos serviços de saúde nas empresas e demais instituições. Constata-se um entrelaçamento entre a precarização da força de trabalho e a "questão" da saúde dos trabalhadores, posto enquanto mediação social que caracteriza esta última, contemporaneamente. Em que pese a "questão", nos termos de Souza (2019), ser um processo social mais amplo que não se constitui apenas na precarização - portanto, imbricado na totalidade do antagonismo entre capital e trabalho; soerguido, de fato, da precariedade estrutural inerente ao processo de produção capitalista -, na sua face mais atual, mais do que nunca, possui uma importante interseção com a precarização - essa forma histórica de reposição política da precariedade estrutural -, inclusive enquanto uma de suas dimensões específicas.

A partir dessa mediação e para além dela, deve-se ressaltar a origem dessa questão ante o antagonismo entre capital e trabalho. Isto é, enquanto processo social que expressa esse paradoxo irremediável, reproduzindo o seu caráter contraditório no bojo da própria saúde, porquanto a destruição dela está, de forma intrínseca, associada à exploração da força de trabalho. Não obstante, exige respostas por parte do capital na tentativa de remediar as dimensões da questão que lhe ameaçam, já que não existe capital sem trabalho. Que no plano político isso passe por metamorfoses que pareçam conferir ao campo alguma solidez ante a defesa da condição de emprego (lembremos, forjada pelo próprio capital), não significa que a direção da crítica aos efeitos da precarização sobre a saúde deva ser no sentido, prioritariamente, de recuperação do pleno emprego e, a reboque, o fortalecimento dos campos que lidam com a relação trabalhosaúde.

\section{Referências}

ALVES, G. Dimensões da reestruturação produtiva: ensaios de sociologia do trabalho. $2^{a}$ edição. Londrina: Praxis; Bauru: Canal 6, 2007. 
. Trabalho, subjetividade e capitalismo manipulatório: o novo metabolismo social do trabalho e a precarização do homem que trabalha. Revista da RET. São Paulo, ano V, n. 8, maio 2011.

ANTUNES, R. As novas formas de acumulação do capital e as formas contemporâneas de estranhamento (alienação). Caderno CRH, Salvador, v. 15, n. 37, p. 23-46, jul. / dez. 2002.

. Proletariado digital, serviços e valor. In: ANTUNES, Ricardo (Org.).

Riqueza e miséria do trabalho no Brasil IV: trabalho digital, autogestão e expropriação da vida: o mosaico da exploração. São Paulo: Editora Boitempo, 2019.

. ; PRAUN, L. A sociedade dos adoecimentos no trabalho. Serv. Soc.

Soc. São Paulo, n. 123, p. 407-427, jul. / set. 2015

APPAY, B. Précarisation sociale e restruturations produtives. In: APPAY B, THEBAUD-MONY, A. (Org.) Précarisation sociale, travail e santé. Paris, 1997.

BRAGA, R. Precariado e sindicalismo no Brasil contemporâneo: um olhar a partir da indústria do call center. Revista Crítica de Ciências Sociais, n. 103, p. 25-52, maio. 2014.

Rebeldia do precariado: trabalho e neoliberalismo no Sul global. São Paulo: Boitempo, 2017.

A política do precariado: do populismo à hegemonia lulista. São Paulo: Boitempo, 2012.

CAZUZA; BRANDÃO, A. O tempo não para. In: O tempo não para. Rio de Janeiro: Polygram,1988.

DRUCK, G. A precarização social do trabalho no Brasil: alguns indicadores.

Riqueza e miséria do trabalho no Brasil II. São Paulo: Boitempo, 2013.

FONTES, V. Capitalismo em tempos de uberização: do emprego ao trabalho.

Marx e o Marxismo, v. 5, n. 8, jan/jun. 2017.

FRANCO, T.; DRUCK, G; SELIGMANN-SILVA, E. As novas relações de trabalho, o desgaste mental do trabalhador e os transtornos mentais no trabalho precarizado. Rev. bras. Saúde ocup., São Paulo, v. 35, n.122, p. 229-248, jul. / dez. 2010. 
HARVEY, D. Condição pós-moderna: uma pesquisa sobre as origens da mudança cultural. São Paulo: Editora Loyola, 1992.

LACAZ, F. A. de C. Saúde dos trabalhadores: cenário e desafios. Cad. Saúde Públ. Rio de Janeiro, v. 13, supl. 2, p. 7-19, 1997

LAURELL, A. C.; NORIEGA, M. Processo de produção e saúde: trabalho e desgaste operário. São Paulo: HUCITEC, 1989.

MACHADO, J. M. H. Processo de vigilância em saúde do trabalhador. Cadernos de Saúde Pública. Rio de Janeiro, v. 13, supl. 2 , p. 33-45, 1997.

MACHADO DA SILVA, L.A. Da informalidade à empregabilidade: reorganizando a dominação no mundo do trabalho. Caderno CRH, Salvador, v.15, n. 37, p. 81-109, jul./dez. 2002.

MELO, A. I. S. C. de. Contracena de diferentes: a saúde dos trabalhadores como prática social e a percepção dos trabalhadores. Orientadora: Sebastiana Rodrigues de Brito. 1993. Dissertação (Mestrado em Serviço Social) - PUC, Rio de Janeiro, 1993.

.; SOUZA, D. de O.; VASCONCELLOS, L.C.F. de. Verbete: saúde do(s) trabalhador(es): a "questão" e o "campo". In: MENDES, R. (Org.). Dicionário de saúde e segurança do trabalhador: conceitos, definições, história, cultura. São Paulo: Proteção, 2018.

MÉSZÁROS, I. Desemprego e precarização: um grande desafio para a esquerda. In: ANTUNES, R. Riqueza e miséria do trabalho no Brasil. São Paulo: Editora Boitempo, 2006.

. A crise estrutural do capital. São Paulo: Boitempo, 2009.

MINAYO-GOMEZ; C.; VASCONCELLOS, L.C.F. de; MACHADO, J.M.H. Saúde do trabalhador: aspectos históricos, avanços e desafios no Sistema Único de Saúde. Ciência \& Saúde Coletiva, v. 23, n. 6, p. 1963-1970, jun. 2018. .; THEDIM-COSTA, S.M.F. A construção do campo da saúde do trabalhador: percursos e dilemas. Cadernos de Saúde Pública. Rio de Janeiro, v.13, supl. 2, p. 21-32, 1997.

ODDONE, I. et al. Ambiente de trabalho: a luta dos trabalhadores pela saúde. Trad. Salvador O. Freitas. São Paulo: Hucitec, 1986.

OLIVEIRA, F. A dominação globalizada: estrutura e dinâmica da dominação burguesa no Brasil. In: BASUALDO, E. M.; ARCEO, E. Neoliberalismo y 
sectores dominantes: tendencias globales y experiencias nacionales. Buenos Aires: CLACSO, 2006.

Crítica à razão dualista/O Ornitorrinco. São Paulo: Boitempo, 2003.

POCHMANN, M. O trabalho sob fogo cruzado. São Paulo: Editora Contexto, 1999.

O emprego na globalização: a nova divisão internacional do trabalho e os caminhos que o Brasil escolheu. São Paulo: Boitempo Editorial, 2001. SELIGMANN-SILVA, E. Desgaste mental no trabalho dominado. São Paulo. Hucitec, 1994.

SLEE, T. Uberização: a nova onda do trabalho precarizado. São Paulo: Editora Elefante, 2017.

SOUZA, D. de O. Saúde do(s) trabalhador(es): análise ontológica da "questão" e do "campo". Maceió: Edufal, 2019.

.; MELO, A. I S. C. de; VASCONCELLOS, L.C.F. de. A saúde dos trabalhadores em "questão": anotações para uma abordagem histórico-ontológica. O Social em Questão, Rio de Janeiro, n. 34, ano 18, jul. / dez. 2015.

STANDING, G. Precariado: a nova classe perigosa. Belo Horizonte: Autêntica, 2013

- O precariado e a luta de classes. Revista Crítica de Ciências Sociais. Coimbra, n.103, p. 9-24, maio. 2014. 
